Article

\title{
Conversion of Furans by Baeyer-Villiger Monooxygenases
}

\author{
Hemant Kumar and Marco W. Fraaije * \\ Molecular Enzymology Group, Groningen Biomolecular Sciences and Biotechnology Institute, \\ University of Groningen, Nijenborgh 4, 9747 AG Groningen, The Netherlands; h.kumar@rug.nl \\ * Correspondence: m.w.fraaije@rug.nl; Tel.: +31-503-634-345
}

Academic Editor: Manuel Ferrer

Received: 12 May 2017; Accepted: 2 June 2017; Published: 7 June 2017

\begin{abstract}
Various furans are considered as valuable platform chemicals as they can be derived from plant biomass. Yet, for their exploitation, follow-up chemistry is required. Here we demonstrate that Baeyer-Villiger monooxygenases (BVMOs) can be used as biocatalysts for the selective oxidation of several furans, including 5-(hydroxymethyl) furfural (HMF) and furfural. A total of 15 different BVMOs were tested for their activity on furfural, which revealed that most of the biocatalysts were active on this aromatic aldehyde. Phenylacetone monooxygenase (PAMO) and a mutant thereof $\left(\mathrm{PAMO}_{\mathrm{M} 446 \mathrm{G}}\right)$ were selected for studying their biocatalytic potential in converting furfural and some other furans. While BVMOs are usually known to form an ester or lactone as a 'normal' product by inserting an oxygen atom adjacent to the carbonyl carbon of the substrate, our results reveal that both biocatalysts produce furanoid acids as the main product from the corresponding aldehydes. Altogether, our study shows that BVMOs can be employed for the selective oxidation of furans.
\end{abstract}

Keywords: biocatalysis; Baeyer-Villiger monooxygenases; furfural; 5-hydroxymethyl furfural

\section{Introduction}

Due to limited fossil reserves and concern over environmental pollution, the search for new routes towards biomass-derived products has intensified in the last decade. One class of compounds that can be easily prepared from plant biomass are furans. These aromatic compounds can be prepared from lignocellulose material by the acid-catalysed dehydration of sugars. Known plant biomass-derived furans are furfural and 5-(hydroxymethyl)furfural (HMF) [1]. HMF is regarded as a highly promising platform chemical for the synthesis of furan-2,5-dicarboxylic acid (FDCA). FDCA can be used for the synthesis of polyethylene furanoate (PEF), a promising polyester. Besides PEF, there are various other compounds of interest that can be synthesized using FDCA as a starting material [2]. The conversion of HMF into FDCA involves a cascade of oxidation reactions involving 2,5-diformylfuran (DFF), 5-formyl-2-furancarboxylic acid (FFA) as a possible intermediate. Furfural is also considered as a renewable platform chemical with high potential as it can serve as a precursor for many types of value-added products [3].

The oxidation of HMF or other furans to FDCA has been achieved mainly by metal-based catalysis [4-7]. Yet, the search for an efficient chemical process for converting HMF into valuable building blocks such as FDCA is still ongoing. As an alternative to metal-based procedures, fermentative and biocatalytic approaches are also explored. Only a few biocatalytic or fermentative methods have been described for the production of FDCA starting from HMF. A bacterial flavoprotein oxidase was shown to be capable of performing the complete oxidation of HMF into FDCA $[8,9]$. Similar results were obtained by using a combination of two or more enzymes $[10,11]$.

Baeyer-Villiger monooxygenases (BVMOs) have been very well studied in the last few decades for their performance of a plethora of selective oxidative reactions [12-14]. They are mainly known to 
catalyse Baeyer-Villiger oxidations by incorporating a single oxygen atom adjacent to the carbonyl carbon to form an ester or lactone. Yet, BVMOs are also capable of carrying out other oxygenation reactions such as epoxidations [15] and sulfoxidations [16]. The oxygen atom inserted in the substrate comes from molecular oxygen while an external reductant such as $\mathrm{NAD}(\mathrm{P}) \mathrm{H}$ is required. The oxygenation reactions are typically catalysed with high enantio-, chemo-, and/or regioselectivity. As these biocatalysts operate in the absence of harmful reagents, they offer advantage over their chemical counterparts. Yet, several factors limit the application of BVMOs. One of these is the fact that they require $\mathrm{NAD}(\mathrm{P}) \mathrm{H}$ as a coenzyme, which is expensive. The BVMOs used in this study have been produced fused to phosphite dehydrogenase (PTDH). Such PTDH-BVMO fusions can utilize phosphite for the efficient recycling of NADPH [17].

Some previous studies have shown that BVMOs can also accept aldehydes as a substrate [18-21]. In these cases, the formed product (the respective acid and/or ester) varied depending on the enzyme and substrate employed. The ability of BVMOs to perform Baeyer-Villiger oxidations and other oxygenations lies in the ability of these enzymes to form a reactive peroxyflavin intermediate. In the case of a Baeyer-Villiger oxidation, the attack of the peroxyflavin on the carbonylic carbon results in the formation of a Criegee intermediate. Depending on the type of substrate and the microenvironment formed by the flavin cofactor, the nicotinamide cofactor, and active site residues, the Criegee intermediate will decay to form the final oxygenated product. In the case of aldehydes, both the typical Baeyer-Villiger product (the formyl ester) and/or the acid product can be formed (see Figure 1). To the best of our knowledge, there are no previous reports on enzymatic Baeyer-Villiger oxidations of HMF or related furanoid aldehydes.

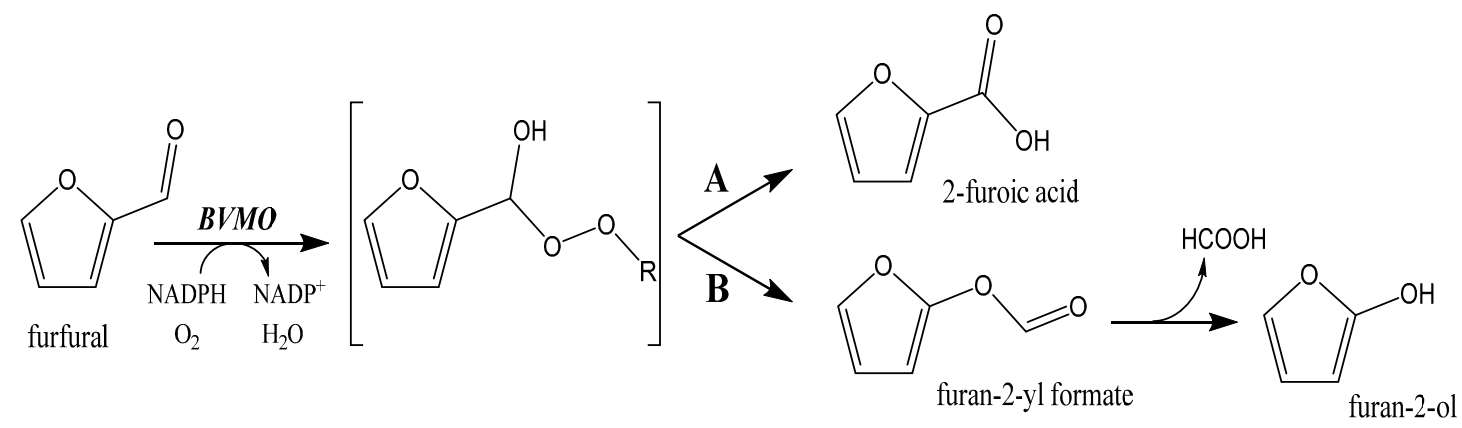

Figure 1. Example of the biocatalytic oxidation of furfural by the action of a Baeyer-Villiger monooxygenase (BVMO). The reactive peroxyflavin enzyme intermediate of a BVMO will form a Criegee intermediate leading to 2-furoic acid (route A) or to the typical Baeyer-Villiger oxidation product, the formyl ester (route B). The formyl ester undergoes hydrolysis in an aqueous solution.

As part of our efforts to develop BVMOs as valuable biocatalysts, we have studied these enzymes for the first time on furanoid aldehydes. Thus, we have checked a collection of 15 distinct BVMOs in the oxidation of furfural. Intriguingly, most of the tested BVMOs showed significant activity on furfural. We selected the thermostable phenylacetone monooxygenase (PAMO) and a specific PAMO mutant $\left(\mathrm{PAMO}_{\mathrm{M} 446 \mathrm{G}}\right)$ for a more detailed biocatalytic study. PTDH-PAMO and mutants thereof have been well studied, are easily expressed, and represent rather robust biocatalysts [17]. This revealed the ability of PAMO and the PAMO mutant to convert furfural, HMF, and related compounds.

\section{Results and Discussion}

\subsection{Exploring BVMOs for Activity on Furfural and $H M F$}

To establish whether BVMOs display activity on furans, we tested 15 BVMOs. With our previously developed expression strategy in which a BVMO is expressed as a PTDH fusion protein, or by using the pBAD expression vector, good to excellent expression levels of all studied BVMOs could be achieved. 
Because the proteome of the expression host, Escherichia coli, is known to be void of any BVMO, cell extracts were used to screen for BVMO activity on the test furan, furfural. As a control, the extract of uninduced cells was also used. While we first attempted to measure the rate of furfural conversion by monitoring NADPH consumption, we noted that uninduced cell extracts also showed significant background activity. This is probably due to endogenous NADPH-dependent aldehyde reductase activity present in E. coli. In fact, using HPLC analysis, we could confirm that $E$. coli cell extract can be used to reduce HMF into the corresponding alcohol, 5-(hydroxymethyl)furfuryl alcohol. To avoid such false positive results, we decided to measure BVMO activity by monitoring oxygen consumption upon the addition of a substrate. Figure 2 shows the observed specific activities.

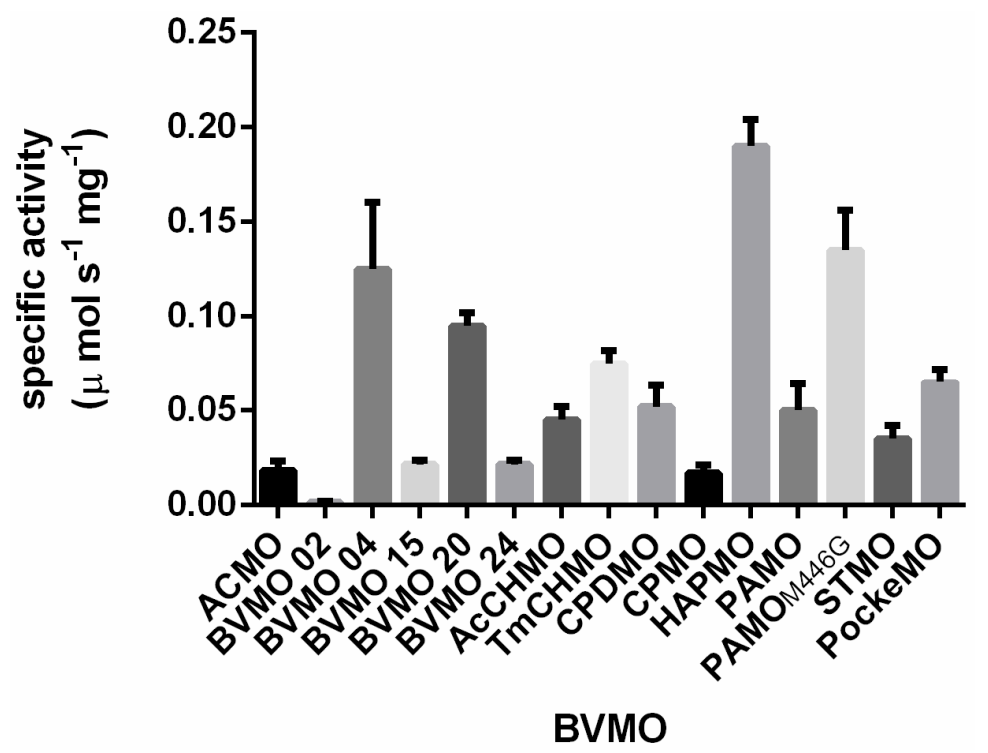

Figure 2. Specific activities of BVMOs on furfural.

All tested BVMOs except BVMO02 showed significant activity towards furfural. From the BVMOs that showed the highest activities, we selected $\mathrm{PAMO}_{\mathrm{M} 446 \mathrm{G}}$ for further biocatalytic exploration, as this enzyme is highly thermostable and solvent tolerant [22]. In fact, for the same reason we also included wild-type PAMO as it still displayed activity on furfural and it is known to exhibit differences in enantio- and regioselectivity when compared with $\mathrm{PAMO}_{\mathrm{M} 446 \mathrm{G}}$ [20]. All subsequent experiments were carried out using purified enzymes to exclude possible background activities.

\subsection{Kinetic Analysis}

To explore the efficiency of PAMO and $\mathrm{PAMO}_{\mathrm{M} 446 \mathrm{G}}$ on furans, a steady-state kinetic analysis was performed using purified enzymes and furfural, HMF, DFF, and FFA as potential substrates. This confirmed that both biocatalysts displayed significant activity towards furfural, HMF, and DFF (Table 1). Also, with FFA some activity was observed but the observed activity at the highest FAA concentration was relatively low $\left(<0.1 \mathrm{~s}^{-1}\right)$. This may be due to the fact that the BVMOs are typically active on non-charged compounds. The kinetic parameters for furfural, HMF, and DFF revealed that similar $k_{\text {cat }}$ values are achieved when compared with the native substrate phenylacetone, while the $\mathrm{K}_{\mathrm{m}}$ values are relatively high. For some combinations of substrate and enzyme, substrate inhibition was observed. Substrate inhibition has been observed before for other BVMOs and may reflect multiple binding modes of the substrate near or in the active site. It is worth noting that the observed activities were lower when the enzymes were pre-incubated with the furanoid substrates for a few minutes. This effect was dependent on the specific furan and more severe at higher concentrations. Such apparent enzyme inactivation may be due to the reactive aldehyde groups of the substrates. 
Table 1. Steady-state kinetic parameters of PAMO and $\mathrm{PAMO}_{\mathrm{M} 446 \mathrm{G}}$ for furanoid aldehydes.

\begin{tabular}{|c|c|c|c|c|c|c|c|c|}
\hline \multirow[b]{2}{*}{ Substrate } & \multicolumn{4}{|c|}{ PAMO } & \multicolumn{4}{|c|}{ PAMO $_{\text {M446G }}$} \\
\hline & $k_{\mathrm{cat}}\left(\mathrm{s}^{-1}\right)$ & $\mathrm{K}_{\mathrm{m}}(\mathrm{mM})$ & $\mathrm{K}_{\mathrm{i}}(\mathrm{mM})$ & $\begin{array}{c}k_{\text {cat }} / K_{\mathrm{m}} \\
\left(\mathrm{s}^{-1} \mathrm{mM}^{-1}\right)\end{array}$ & $k_{\mathrm{cat}}\left(\mathrm{s}^{-1}\right)$ & $\mathrm{K}_{\mathrm{m}}(\mathrm{mM})$ & $\mathrm{K}_{\mathrm{i}}(\mathrm{mM})$ & $\begin{array}{c}k_{\text {cat }} / K_{\mathrm{m}} \\
\left(\mathrm{s}^{-1} \mathrm{mM}^{-1}\right)\end{array}$ \\
\hline Furfural & $2.8 \pm 0.3$ & $2.2 \pm 0.5$ & $36.9 \pm 9.8$ & 1.2 & $7 \pm 0.8$ & $17.3 \pm 1.3$ & $6.4 \pm 0.5$ & 0.4 \\
\hline $\begin{array}{l}\text { 5-(hydroxymethyl)furfural } \\
\text { (HMF) }\end{array}$ & $1.4 \pm 0.1$ & $16.9 \pm 3.3$ & n.d. & 0.08 & $0.67 \pm 0.1$ & $20.5 \pm 2.3$ & n.d. & 0.03 \\
\hline 2,5-diformylfuran (DFF) & $0.3 \pm 0.1$ & $4.3 \pm 2.3$ & n.d. & 0.07 & $1.2 \pm 0.8$ & $5.8 \pm 2.0$ & $10.3 \pm 3.0$ & 0.1 \\
\hline
\end{tabular}

n.d.: no substrate inhibition observed.

\subsection{Product Analysis}

HPLC and NMR were used for product analysis. HPLC methods were derived from previous studies in our laboratory $[9,22]$. Calibration curves for the substrates and possible products (furfural, 2-furoic acid, HMF, DFF, 5-hydroxymethyl-2-furancarboxylic acid (HMFCA), FFA and FDCA) were determined beforehand. The conversion of furfural by PAMO or PAMO $_{M 446 \mathrm{G}}$ resulted in around $60 \%$ conversion after $12 \mathrm{~h}$ (Table 2) with 2-furoic acid as the main product. This shows that BVMOs offer an alternative biocatalytic route towards this furan that can be used as food preservative and flavor. Furfural can also be oxidized into the acid by using alcohol dehydrogenases, but these enzymes may also reduce the furfural into the corresponding alcohol. BVMOs do not exhibit reducing activities as they operate via the oxidizing peroxyflavin enzyme intermediate (see Figure 1). Yet, with PAMO or $\mathrm{PAMO}_{\mathrm{M} 446 \mathrm{G}}$ and furfural, also a tiny other product peak was observed which was probably the formyl ester formed from furfural by a typical Baeyer-Villiger oxidation. Such an ester may undergo hydrolysis to form the corresponding alcohol and formic acid. Since the reference for the respective ester/alcohol was not available, we could not confirm the identity of the minor product.

Table 2. HPLC analysis of conversion of furans by PAMO and $\mathrm{PAMO}_{\mathrm{M} 446 \mathrm{G}}$.

\begin{tabular}{|c|c|c|c|c|c|c|}
\hline \multirow[b]{2}{*}{ Substrate } & \multirow{2}{*}{$\begin{array}{l}\text { Concentration } \\
(\mathrm{mM})\end{array}$} & \multirow{2}{*}{$\begin{array}{l}\text { Reaction } \\
\text { Time (h) }\end{array}$} & \multicolumn{2}{|c|}{ PAMO } & \multicolumn{2}{|c|}{ PAMO $_{\text {M446G }}$} \\
\hline & & & $\begin{array}{l}\text { Concentration } \\
(\mu \mathrm{M})\end{array}$ & $\begin{array}{c}\text { Conversion } \\
(\%)\end{array}$ & $\begin{array}{l}\text { Concentration } \\
(\mu \mathrm{M})\end{array}$ & $\begin{array}{c}\text { Conversion } \\
(\%)\end{array}$ \\
\hline Furfural & 5 & 12 & 5 & 60 & 5 & 60 \\
\hline HMF & 5 & 16 & 5 & 66 & 5 & 85 \\
\hline DFF & 2 & 12 & 5 & 30 & 5 & 98 \\
\hline $\begin{array}{c}\text { 5-formyl-2-furancarboxylic } \\
\text { acid (FFA) }\end{array}$ & 10 & 24 & 10 & 60 & 10 & 90 \\
\hline
\end{tabular}

Similar to what was observed for the conversion of furfural, most of the HMF was largely converted with PAMO or PAMO ${ }_{\mathrm{M} 446 \mathrm{G}}$ after $16 \mathrm{~h}$ of incubation (Table 2). The major product obtained was the corresponding acid (HMFCA). A minor product peak (probably the corresponding ester or alcohol) was also observed but could not be confirmed due to the lack of a reference compound. HPLC analysis of the conversion of $2 \mathrm{mM}$ DFF using $5 \mu \mathrm{M}$ biocatalyst revealed that $\mathrm{PAMO}_{\mathrm{M} 446 \mathrm{G}}$ gave the best result: $98 \%$ conversion after $12 \mathrm{~h}$. The formation of only one product, FFA, was observed, which indicates that again the corresponding acid is formed as the main product. As we noted some activity on FFA, we also incubated this furan with a high enzyme loading $(10 \mu \mathrm{M})$ and for a long reaction time $(24 \mathrm{~h})$. This revealed that both BVMOs were able to produce FDCA (Table 2).

In order to verify the identity of the products formed upon the conversion of HMF, DFF, and FFA, ${ }^{1} \mathrm{H}-\mathrm{NMR}$ analyses were also performed (Figure 3). While preparing samples for ${ }^{1} \mathrm{H}-\mathrm{NMR}$, it was observed that freeze-drying caused significant loss of material. Similar problems have been reported earlier with such aldehydes used as substrates [19]. Hence, extraction at low $\mathrm{pH}$ was performed using ethyl acetate and the obtained material was dried in vacuum. Protonation was found to be essential for effective extraction. The ${ }^{1} \mathrm{H}-\mathrm{NMR}$ spectra clearly identified FFA and FDCA as products upon the conversion of DFF and FFA, respectively (Figure 3 ). ${ }^{1} \mathrm{H}-\mathrm{NMR}$ spectra of the reaction mixture upon the 
conversion of HMF clearly showed that more than one product was formed in the reaction. One of the products is indeed HMFCA, while the other represents the alcohol.

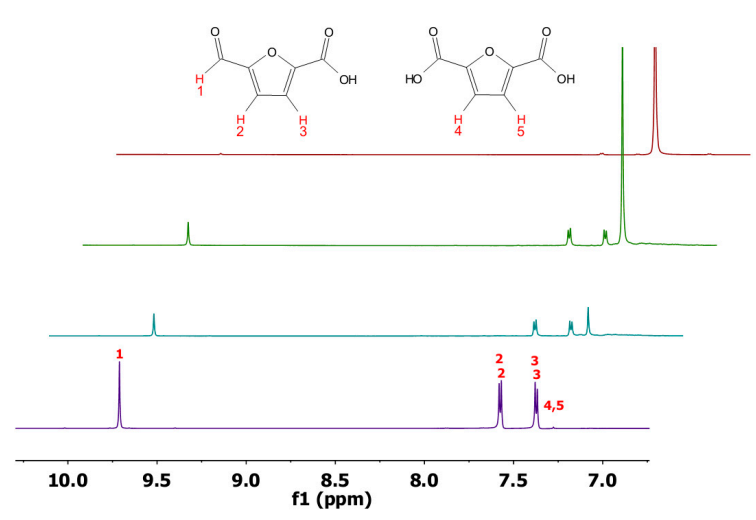

(a)

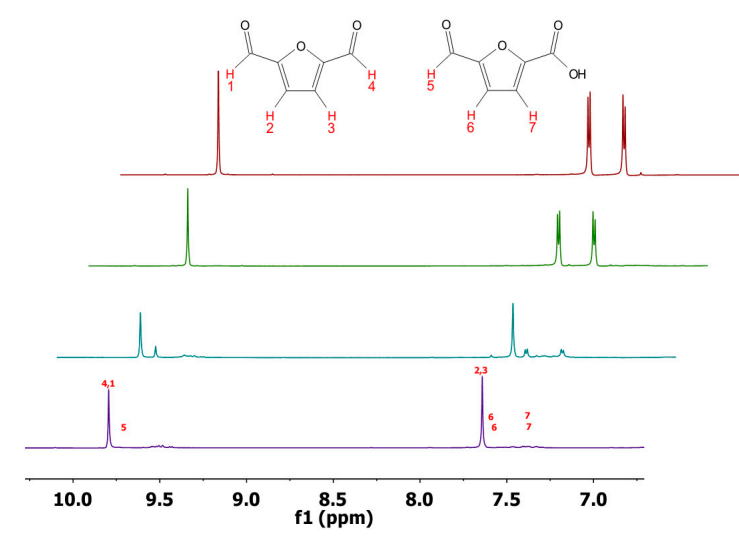

(b)

Figure 3. ${ }^{1} \mathrm{H}-\mathrm{NMR}$ spectra of FFA (a) and DFF (b) conversions. Spectra in purple are the negative controls (without enzyme) and the product reference spectrum is in red. Green spectra are conversions with $\mathrm{PAMO}_{\mathrm{M} 446 \mathrm{G}}$ and blue spectra are conversions with PAMO.

\section{Conclusions}

Our study shows that BVMOs can be used for converting various furanoid aldehydes. Wild type PAMO and PAMO ${ }_{M 446 G}$ were shown to convert the five-membered aromatic aldehydes, furfural, $\mathrm{HMF}$, DFF and FFA, into the corresponding acids as main products. Previous studies on BVMOs had already revealed that some BVMOs act on six-membered aromatic and aliphatic aldehydes as substrates. Branchaud and colleagues found that cyclohexanone monooxygenase converts an aliphatic aldehyde exclusively into the corresponding acid, while a mixture of acid and ester is formed when converting aromatic aldehydes [21]. PAMO, on the other hand, has been shown to exclusively produce the ester product when converting 2-phenylpropionaldehyde [23]. Moonen et al. showed that, unlike chemical $\mathrm{B}-\mathrm{V}$ oxidations of aromatic aldehydes that result in the acid product, BVMO-catalysed oxidations of six-membered aromatic aldehydes with electron withdrawing substituents result mainly in ester products [18]. So it appears that, although the basic mechanism for B-V oxidation is the same, whether it is chemical or enzymatic, enzymes can steer the outcome towards the formation of the acid or ester product.

$\mathrm{PAMO}_{\mathrm{M} 446 \mathrm{G}}$ and PAMO were explored further for kinetic and product analysis. Both BVMOs are able to convert HMF and furfural into the corresponding acids as major products. Also, DFF and FFA were found to be converted into the corresponding acids as main products (FFA and FDCA, respectively). $\mathrm{PAMO}_{\mathrm{M} 446 \mathrm{G}}$ was found to perform slightly better as a biocatalyst when compared with the wild type counterpart. In fact, the rate of conversion of $\mathrm{HMF}$ by $\mathrm{PAMO}_{\mathrm{M} 446 \mathrm{G}}$ is in the same range as the recently discovered HMF oxidase [9]. Yet, as also observed for HMF oxidase, the subsequent steps in oxidizing DFF and FFA are very slow, excluding the use of these BVMOs for the conversion of HMF into FDCA. Furthermore, unfortunately, both studied BVMOs suffer from substrate inhibition and inactivation. Hence, it would be worthwhile to optimize the conditions and/or engineer the enzymes towards better performance. As PAMO is a rather stable enzyme and its structure is known, targeted enzyme engineering may solve the enzyme inactivation by replacing lysine residues that are expected to react with the aldehyde substrates. When engineered into a robust biocatalyst, PAMO or another BVMO may be turned into relevant biocatalytic tools to convert furans into compounds of higher value. We could show that PAMO is a good starting point to develop a biocatalyst that can help in converting HMF or related compounds into FDCA or other furanoid compounds. 


\section{Materials and Methods}

\subsection{Materials}

All chemicals, unless mentioned otherwise, were purchased from Sigma-Aldrich (Zwijndrecht, The Netherlands). HisTrap FF, and HiTrap Q columns were purchased from GE Healthcare (Eindhoven, The Netherlands). For buffer exchange of the purified enzyme samples, DG-10 EconoPac desalting columns from BioRad (Veenendaal, The Netherlands) were used.

\subsection{Expression and Purification}

In-house PTDH-fused BVMO expression constructs for protein production in E. coli were used in this study. Details of the constructs and the source of the respective genes are shown in Table 3. Transformed E. coli TOP10 cells were grown overnight in $5 \mathrm{~mL}$ lysogeny broth (LB) medium containing ampicillin $\left(50 \mu \mathrm{g} \mathrm{mL}^{-1}\right)$. The overnight cultures were diluted 100 times in fresh $5 \mathrm{~mL} \mathrm{LB}$, incubated at $37^{\circ} \mathrm{C}$, and induced with $0.02-0.002 \%$ of arabinose at $\mathrm{OD}_{600} 0.4-0.6$. After induction, cells were grown at different temperatures, depending on the specific expression vector $\left(48 \mathrm{~h}\right.$ at $17^{\circ} \mathrm{C}$ or $36 \mathrm{~h}$ at $\left.24{ }^{\circ} \mathrm{C}\right)$. Cells were harvested using centrifugation $(6000 \times g, 20 \mathrm{~min})$, washed, and resuspended in $500 \mu \mathrm{L}$ of $50 \mathrm{mM}$ phosphate buffer, $\mathrm{pH} 7.5$, and sonicated for $1 \mathrm{~min}$ (Vibra cells; cycles of $5 \mathrm{~s}$ on, $10 \mathrm{~s}$ off). Cell debris was removed by centrifugation at $15,000 \times g$ for $45 \mathrm{~min}$ (JA17 rotor, $4{ }^{\circ} \mathrm{C}$ ) to obtain the cell extracts. Similarly, cell extract was also prepared from non-transformed E. coli TOP10 cells and used as a control. PTDH-PAMO and PTDH-PAMO ${ }_{\mathrm{M} 446 \mathrm{G}}$ were purified as described previously [24]. An additional purification step of $Q$ sepharose chromatography was used to make sure that the enzyme was pure. The yield of purified enzyme per $\mathrm{L}$ of culture broth was $35 \mathrm{mg}$ for PTDH-PAMO

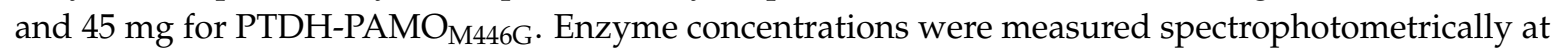
$440 \mathrm{~nm}$ using the molecular extinction coefficient of $12.4 \mathrm{mM}^{-1} \mathrm{~cm}^{-1}$ for protein bound flavin adenine dinucleotide (FAD) [24].

Table 3. PTDH-BVMOs constructs used along with their source organisms.

\begin{tabular}{cccc}
\hline BVMO & Construct & Source & Reference \\
\hline BVMO02 & pCRE2-BVMO02 & Rhodococcus jostii RHA1 & {$[25]$} \\
BVMO04 & pBADNK-BVMO04 & Rhodococcus jostii RHA1 & {$[25]$} \\
BVMO15 & pBADNK-BVMO15 & Rhodococcus jostii RHA1 & {$[25]$} \\
BVMO20 & pBADNK-BVMO20 & Rhodococcus jostii RHA1 & {$[25]$} \\
BVMO24 & pBADNK-BVMO24 & Rhodococcus jostii RHA1 & {$[25]$} \\
HAPMO & pCRE2-HAPMO & Pseudomonas fluorescens ACB & {$[26]$} \\
CPDMO & pCRE2-CPDMO & Pseudomonas sp. strain HI-70 & {$[27]$} \\
ACMO & pCRE2-ACMO & Gordonia sp. strain TY-5 & {$[28]$} \\
AcCHMO & pCRE2-CHMO & Acinetobactor sp. & {$[26]$} \\
TmCHMO & pCRE2-TmCHMO & Thermocrispum municipale & {$[29]$} \\
CPMO & pCRE2-CPMO & Comamonas sp. & {$[26]$} \\
STMO & pCRE2-STMO & Rhodococcus rhodochrous & {$[30]$} \\
PAMO & pCRE2-PAMO & Thermobifida fusca & {$[24]$} \\
PAMOM446G & pCRE2-PAMOM446G & Thermobifida fusca & {$[26]$} \\
PockeMO & pCRE2-PoKeMO & Thermothelomyces thermophila & {$[31]$} \\
\hline
\end{tabular}

\subsection{Kinetic Measurements}

For measuring specific activity, oxygen consumption was measured using a Firesting $\mathrm{O}_{2}$ detector (Pyroscience, Aachen, Germany). For calibration, air-saturated water was used to set the signal at $100 \%$. Nitrogen-flushed water was used as $0 \%$ oxygen solution. Reactions were performed using cell-free extract of induced BVMOs in $50 \mathrm{mM}$ phosphate buffer, $\mathrm{pH} 7.5$ at $25^{\circ} \mathrm{C}$. The reaction volume of $1 \mathrm{~mL}$ contained $2 \mathrm{mM}$ furfural, $100 \mu \mathrm{M} \mathrm{NADPH}$, and $25 \mu \mathrm{L}$ cell-free extract $(0.2-0.4 \mathrm{mg}$ of total protein) of induced cells expressing PTDH-fused BVMO. For measuring kinetic parameter, NADPH 
depletion was monitored at $370 \mathrm{~nm}$ during the first $3 \mathrm{~min}$. NADPH was monitored at $370 \mathrm{~nm}$, and not at $340 \mathrm{~nm}$ as commonly done, to avoid interfering with the absorbance of the furanoid aldehydes. The observed rates were calculated using a molecular extinction coefficient $\left(\varepsilon_{370, \mathrm{NADPH}}\right)$ of $2.7 \mathrm{mM}^{-1} \mathrm{~cm}^{-1}$. For determining the steady-state kinetic parameters with HMF as a substrate, initial activities at 10 different substrate concentrations $(0.5-20 \mathrm{mM})$ were measured. All the kinetic measurements were performed in duplicate using $50 \mathrm{mM}$ phosphate buffer, $\mathrm{pH} 7.5$ at $25{ }^{\circ} \mathrm{C}$, unless mentioned otherwise. DMSO (up to $30 \%$ ) was used to dissolve furfural, DFF, and FFA in stock solutions such that the final DMSO concentration was always less than $5 \%$. For measuring the kinetic parameters of DFF and FFA, oxygen consumption was measured using a Firesting $\mathrm{O}_{2}$ detector (Pyroscience, Aachen, Germany). For calibration, air-saturated water was used to set the signal at 100\%. Nitrogen-flushed water was used as $0 \%$ oxygen solution. Reactions were performed using $50-100 \mathrm{nM}$ of enzyme and $50 \mathrm{mM}$ phosphate buffer, $\mathrm{pH} 7.5$ at $25^{\circ} \mathrm{C}$. The rates of decrease of NADPH/oxygen were converted to observed rates. The Michaelis-Menten equation for substrate inhibition, $\mathrm{V}=\left(k_{\mathrm{cat}} \times[\mathrm{S}]\right) / \mathrm{K}_{\mathrm{m}}+[\mathrm{S}] \times\left(1+\left[\mathrm{S} / \mathrm{K}_{\mathrm{i}}\right)\right)$ was used for curve fitting in order to obtain steady-state kinetic parameters. GraphPad Prism (version 6) software was used for fitting the kinetic data.

\subsection{Product Identification Using HPLC}

For product analysis, $2 \mathrm{~mL}$ samples of $2-10 \mathrm{mM}$ substrate, $100 \mu \mathrm{M}$ NADPH, $50 \mathrm{mM}$ phosphite, 150-200 U catalase, and $5.0 \mu \mathrm{M}$ enzyme were incubated at $25^{\circ} \mathrm{C}$ and $150 \mathrm{rpm}$ for $12 \mathrm{~h}$. Substrates used were 5-hydroxymethylfurfural (HMF), 2,5-diformyl furan (DFF), 5-formyl-2-furoic acid (FFA), and furfural. The reactions were stopped by removing the enzyme using ultrafiltration ( $30 \mathrm{kDa}$ cutoff Amicon ultracentrifugal filters). Reactions with higher substrate concentrations were diluted to $2.0 \mathrm{mM}$ before analysis to avoid overloading of the column. Negative controls (incubations without enzyme) were incubated and analyzed using the same conditions. A Zorbax Eclipse XDB-C8 HPLC column (Agilent, Amstelveen, The Netherlands) was used for the separation of the furanoid substrates and products. Also, $12 \mathrm{mM}$ phosphate buffer at $\mathrm{pH} 7.0$ and $100 \%$ acetonitrile were used as mobile phases A and B respectively. A previously established HPLC method for the separation of furanoid compounds was used [22]. Reference compounds were used to identify and quantify the products.

\subsection{NMR Analysis}

For a large-scale conversion, $20 \mathrm{mM}$ HMF, $30 \mathrm{mM}$ phosphite, $100 \mu \mathrm{M}$ NADPH, $0.5 \mu \mathrm{M}$ PTDH-PAMO or PTDH-PAMO ${ }_{\mathrm{M} 446 \mathrm{G}}$, and 150-200 U catalase in $250 \mathrm{~mL} 50 \mathrm{mM}$ Tris-HCl buffer (pH 7.5) was incubated at $25^{\circ} \mathrm{C}$, while shaking at $150 \mathrm{rpm}$. Then, $25 \mathrm{~mL}$ samples were taken at regular intervals to monitor the formation of products. In the case of DFF and FFA conversions, $10 \mathrm{mM}$ substrate and up to $5 \mu \mathrm{M}$ enzyme was used. Sample preparation was carried out in two ways; ethyl acetate extraction at acidic $\mathrm{pH}$ using $1 \mathrm{~N} \mathrm{HCl}$, and freeze drying. An equal volume of ethyl acetate was mixed with the acidified sample. After rigorous mixing, the organic phase was collected and dried. Subsequently, $5 \mathrm{mg}$ of dry sample was mixed with $700 \mu \mathrm{L}$ deuterated DMSO and filtered before NMR analysis. In the case of freeze-drying, the 25-mL sample was frozen in liquid nitrogen and subsequently lyophilized to obtain a dry sample. For NMR analysis, again, $700 \mu \mathrm{L}$ deuterated DMSO was added. The samples were analyzed by NMR (Varian Unity Plus 1H: $400 \mathrm{MHz}$ spectrometer). Mesternova software was used to analyze the data and ChemDraw software was used to predict the NMR resonance peaks of unknown compounds.

Acknowledgments: We would like to thank Erasmus mundus 'Svaagata' for providing a PhD scholarship to Hemant Kumar. We would also like to thank Patrícia Bulegon Brondani and Yasser Gabber for initial experiments and for their suggestions.

Author Contributions: H.K. and M.W.F. conceived and designed the experiments; H.K. performed the experiments; H.K. and M.W.F. analyzed the data, contributed reagents/materials/analysis tools and wrote the paper.

Conflicts of Interest: The authors declare no conflict of interest. 


\section{References}

1. Zhou, P.; Zhang, Z. One-pot catalytic conversion of carbohydrates into furfural and 5-hydroxymethylfurfural. Catal. Sci. Technol. 2016, 6, 3694-3712. [CrossRef]

2. Sousa, A.F.; Vilela, C.; Fonseca, A.C.; Matos, M.; Freire, C.S.R.; Gruter, G.-J.M.; Coelho, J.F.J.; Silvestre, A.J.D. Biobased polyesters and other polymers from 2,5-furandicarboxylic acid: A tribute to furan excellency. Polym. Chem. 2015, 6, 5961-5983. [CrossRef]

3. Mariscal, R.; Maireles-Torres, P.; Ojeda, M.; Sádaba, I.; López Granados, M. Furfural: A renewable and versatile platform molecule for the synthesis of chemicals and fuels. Energy Environ. Sci. 2016, 9, 1144-1189. [CrossRef]

4. Zhang, Z.; Zhen, J.; Liu, B.; Lv, K.; Deng, K. Selective aerobic oxidation of the biomass-derived precursor 5-hydroxymethylfurfural to 2,5-furandicarboxylic acid under mild conditions over a magnetic palladium nanocatalyst. Green Chem. 2015, 17, 1308-1317. [CrossRef]

5. Yi, G.; Teong, S.P.; Zhang, Y. Base-free conversion of 5-hydroxymethylfurfural to 2,5-furandicarboxylic acid over a Ru/C catalyst. Green Chem. 2016, 18, 979-983. [CrossRef]

6. Li, S.; Su, K.; Li, Z.; Cheng, B. Selective oxidation of 5-hydroxymethylfurfural with $\mathrm{H}_{2} \mathrm{O}_{2}$ catalyzed by a molybdenum complex. Green Chem. 2016, 18, 2122-2128. [CrossRef]

7. Mei, N.; Liu, B.; Zheng, J.; Lv, K.; Tang, D.; Zhang, Z. A novel magnetic palladium catalyst for the mild aerobic oxidation of 5-hydroxymethylfurfural into 2,5-furandicarboxylic acid in water. Catal. Sci. Technol. 2015, 5, 3194-3202. [CrossRef]

8. Dijkman, W.P.; Binda, C.; Fraaije, M.W.; Mattevi, A. Structure-based enzyme tailoring of 5-hydroxymethylfurfural oxidase. ACS Catal. 2015, 5, 1833-1839. [CrossRef]

9. Dijkman, W.P.; Groothuis, D.E.; Fraaije, M.W. Enzyme-catalyzed oxidation of 5-hydroxymethylfurfural to furan-2,5-dicarboxylic acid. Angew. Chem. Int. Ed. Engl. 2014, 53, 6515-6518. [CrossRef] [PubMed]

10. McKenna, S.M.; Leimkühler, S.; Herter, S.; Turner, N.J.; Carnell, A.J. Enzyme cascade reactions: Synthesis of furandicarboxylic acid (FDCA) and carboxylic acids using oxidases in tandem. Green Chem. 2015, 17, 3271-3275. [CrossRef]

11. Carro, J.; Ferreira, P.; Rodríguez, L.; Prieto, A.; Serrano, A.; Balcells, B.; Ardá, A.; Jiménez-Barbero, J.; Gutiérrez, A.; Ullrich, R.; et al. 5-Hydroxymethylfurfural conversion by fungal aryl-alcohol oxidase and unspecific peroxygenase. FEBS J. 2015, 282, 3218-3229. [CrossRef] [PubMed]

12. Bucko, M.; Gemeiner, P.; Schenkmayerova, A.; Krajcovic, T.; Rudroff, F.; Mihovilovic, M.D. Baeyer-Villiger oxidations: Biotechnological approach. Appl. Microbiol. Biotechnol. 2016, 100, 6585-6599. [CrossRef] [PubMed]

13. Leisch, H.; Morley, K.; Lau, P.C.K. Baeyer-Villiger monooxygenases: More than just green chemistry. Chem. Rev. 2011, 111, 4165-4222. [CrossRef] [PubMed]

14. Torres Pazmiño, D.E.; Dudek, H.M.; Fraaije, M.W. Baeyer-Villiger monooxygenases: Recent advances and future challenges. Curr. Opin. Chem. Biol. 2010, 14, 138-144. [CrossRef] [PubMed]

15. Colonna, S.; Gaggero, N.; Carrea, G.; Ottolina, G.; Pasta, P.; Zambianchi, F. First asymmetric epoxidation catalysed by cyclohexanone monooxygenase. Tetrahedron Lett. 2002, 43, 1797-1799. [CrossRef]

16. Brondani, P.B.; de Gonzalo, G.; Fraaije, M.W. Recent developments in flavin-based catalysis. In Green Biocatalysis, 1st ed.; Patel, R.N., Ed.; John Wiley \& Sons: Hoboken, NJ, USA, 2013; Volume 5, pp. $403-415$.

17. Torres Pazmiño, D.E.; Snajdrova, R.; Baas, B.-J.; Ghobrial, M.; Mihovilovic, M.D.; Fraaije, M.W. Self-sufficient Baeyer-Villiger monooxygenases: Effective coenzyme regeneration for biooxygenation by fusion engineering. Angew. Chem. Int. Ed. 2008, 47, 2275-2278. [CrossRef] [PubMed]

18. Moonen, M.J.H.; Westphal, A.H.; Rietjens, I.M.C.M.; Van Berkel, W.J.H. Enzymatic Baeyer-Villiger oxidation of benzaldehydes. Adv. Synth. Catal. 2005, 347, 1027-1034. [CrossRef]

19. Bisagni, S.; Summers, B.; Kara, S.; Hatti-Kaul, R.; Grogan, G.; Mamo, G.; Hollmann, F. Exploring the substrate specificity and enantioselectivity of a Baeyer-Villiger monooxygenase from Dietzia sp. D5: Oxidation of sulfides and aldehydes. Top. Catal. 2013, 57, 366-375. [CrossRef]

20. Torres Pazmiño, D.E.; Snajdrova, R.; Rial, D.V.; Mihovilovic, M.D.; Fraaije, M.W. Altering the substrate specificity and enantioselectivity of phenylacetone monooxygenase by structure-inspired enzyme redesign. Adv. Synth. Catal. 2007, 349, 1361-1368. [CrossRef] 
21. Branchaud, B.P.; Walsh, C.T. Functional group diversity in enzymatic oxygenation reactions catalyzed by bacterial flavin-containing cyclohexanone oxygenase. J. Am. Chem. Soc. 1985, 107, 2153-2161. [CrossRef]

22. Dijkman, W.P.; Fraaije, M.W. Discovery and characterization of a 5-hydroxymethylfurfural oxidase from Methylovorus sp. strain MP688. Appl. Environ. Microbiol. 2014, 80, 1082-1090. [CrossRef] [PubMed]

23. Rodríguez, C.; de Gonzalo, G.; Fraaije, M.W.; Gotor, V. Enzymatic kinetic resolution of racemic ketones catalyzed by Baeyer-Villiger monooxygenases. Tetrahedron: Asymmetry 2007, 18, 1338-1344. [CrossRef]

24. Fraaije, M.W.; Wu, J.; Heuts, D.P.H.M.; van Hellemond, E.W.; Spelberg, J.H.L.; Janssen, D.B. Discovery of a thermostable Baeyer-Villiger monooxygenase by genome mining. Appl. Microbiol. Biotechnol. 2005, 66, 393-400. [CrossRef] [PubMed]

25. Riebel, A.; Dudek, H.M.; de Gonzalo, G.; Stepniak, P.; Rychlewski, L.; Fraaije, M.W. Expanding the set of rhodococcal Baeyer-Villiger monooxygenases by high-throughput cloning, expression and substrate screening. Appl. Microbiol. Biotechnol. 2012, 95, 1479-1489. [CrossRef] [PubMed]

26. Torres Pazmiño, D.E.; Riebel, A.; de Lange, J.; Rudroff, F.; Mihovilovic, M.D.; Fraaije, M.W. Efficient biooxidations catalyzed by a new generation of self-sufficient Baeyer-Villiger monooxygenases. ChemBioChem 2009, 10, 2595-2598. [CrossRef] [PubMed]

27. Iwaki, H.; Wang, S.; Grosse, S.; Bergeron, H.; Nagahashi, A.; Lertvorachon, J.; Yang, J.; Konishi, Y.; Hasegawa, Y.; Lau, P.C.K. Pseudomonad cyclopentadecanone monooxygenase displaying an uncommon spectrum of Baeyer-Villiger oxidations of cyclic ketones. Appl. Environ. Microbiol. 2006, 72, 2707-2720. [CrossRef] [PubMed]

28. Kotani, T.; Yamamoto, T.; Yurimoto, H.; Sakai, Y.; Kato, N. Propane monooxygenase and NAD ${ }^{+}$-dependent secondary alcohol dehydrogenase in propane metabolism by Gordonia sp. strain TY-5. J. Bacteriol. 2003, 185, 7120-7128. [CrossRef] [PubMed]

29. Romero, E.; Castellanos, J.R.G.; Mattevi, A.; Fraaije, M.W. Characterization and crystal structure of a robust cyclohexanone monooxygenase. Angew. Chem. Int. Ed. Engl. 2016, 55, 15852-15855. [CrossRef] [PubMed]

30. Franceschini, S.; van Beek, H.L.; Pennetta, A.; Martinoli, C.; Fraaije, M.W.; Mattevi, A. Exploring the structural basis of substrate preferences in Baeyer-Villiger monooxygenases: Insight from steroid monooxygenase. J. Biol. Chem. 2012, 287, 22626-22634. [CrossRef] [PubMed]

31. Fürst, M.J.L.J.; Savino, S.; Dudek, H.M.; Gómez Castellanos, J.R.; Gutiérrez de Souza, C.; Rovida, S.; Fraaije, M.W.; Mattevi, A. Polycyclic ketone monooxygenase from the thermophilic fungus Thermothelomyces thermophila: A structurally distinct biocatalyst for bulky substrates. J. Am. Chem. Soc. 2017, 139, 627-630. [CrossRef] [PubMed]

(C) 2017 by the authors. Licensee MDPI, Basel, Switzerland. This article is an open access article distributed under the terms and conditions of the Creative Commons Attribution (CC BY) license (http:/ / creativecommons.org/licenses/by/4.0/). 